\title{
The validity and accuracy of MRI arthrogram in the assessment of painful articular disorders of the hip
}

Rajeev A, Tuinebreijer WE, Mohamed A, Newby M. 


\section{ABSTRACT}

The assessment of a patient with chronic hip pain can be challenging. The differential diagnosis of intraarticular pathology causing hip pain can be diverse. These includes conditions such as osteoarthritis, fracture, and avascular necrosis, synovitis, loose bodies, labral tears, articular pathology and femoro-acetabular impingement. Magnetic resonance imaging (MRI) arthrography of the hip has been widely used now for diagnosis of articular pathology of the hip.

A retrospective analysis of 113 patients who had MRI arthrogram and who underwent hip arthroscopy were included in the study. The MRI arthrogram was performed using gadolinium injection and reported by a single radiologist. The findings were then compared to that found on arthroscopy. The sensitivity, specificity, positive predictive value (PPV), negative predictive value (NPV), accuracy and 95\%confidence interval (CI) were calculated for each pathology.

Labral tear-Sensitivity $84 \%$ (74.3-90.5), Specificity $64 \%$ (40.7-82.8), PPV $91 \%$ (82.1-95.8), NPV 48\% (29.5-67.5), accuracy 80\%. Delamination-Sensitivity 7\% (0.822.1), Specificity 98\% (91.6-99.7), PPV 50\% (6.8-93.2), NPV 74\% (65.1-82.2) and accuracy $39 \%$. Chondral changes-Sensitivity $25 \%(13.3-38.9)$, Specificity $83 \%$ (71.3-91.1), PPV 52\%(30.6-73.2), NPV 59\% (48.0-69.2) and accuracy 58\%. Femoral-acetabular impingement (CAM deformity)-Sensitivity 34\% (19.6-51.4), Specificity $83 \%$ (72.290.4), PPV 50\% (29.9-70.1), NPV 71\% (60.6-80.5) and accuracy 66\%. SynovitisSensitivity 11\% (2.3-28.2), Specificity 99\% (93.6-100), PPV 75\% (19.4-99.4), NPV 77\% (68.1-84.6) and accuracy $77 \%$.

Our study conclusions are MRI arthrogram is a useful investigation tool in detecting labral tears, it is also helpful in the diagnosis of femoral-acetabular impingement. However when it comes to the diagnosis of chondral changes, defects and cartilage delamination the sensitivity and accuracy is low.

Keywords: MRI arthrogram, Validity, Accuracy, Articular pathology. 


\section{INTRODUCTION}

The complex anatomy and biomechanics of the hip makes the diagnosis of hip pathology very challenging [1]. The use of plain magnetic resonance imaging (MRI) is a usual imaging investigation to detect bone and soft tissue pathologies of the hip joint [2]. But it is limited in the evaluation of acetabular labral tears, cartilage defects and loose bodies [3]. MRI arthrograms is reported to have high sensitivity and specificity in the diagnosis of articular disorders of the hip[4]. MRI arthrogram with injection of contrast agent like gadolinium gives better detection of labral pathology[5]

Hip arthroscopy is considered as the gold standard for the diagnosis of intra articular pathologies and initiate appropriate treatment [6]. Recently hip arthroscopy has been widely used for the diagnosis and treatment of hip intra-articular disorders [7, 8]. But the use of hip arthroscopy as a diagnostic tool is not accepted among hip surgeons as it is invasive and costly[9]. This has led to the development and improvement in the technique and interpretation of MRI arthrograms so that an accurate diagnosis can be established before performing the hip arthroscopy[10].

In our study we compared the MRI arthrogram findings reported by a single radiologist to that of the pathologies found during hip arthroscopy. The sensitivity, specificity, positive predictive value (PPV), negative predictive value (NPV) and accuracy in the diagnosis of various hip pathology including labral tear, delamination and chondral changes, femoral-acetabular impingement (CAM and pincer lesion) and synovitis are calculated for MRI arthrogram.

\section{MATERIALS AND METHODS}

The patients who were included in the study were a consecutive series of 113 cases seen in the Hip clinic, referred with complaints of painful hip disorders. The outpatient work up included a detailed history taking and clinical examination of the hip which consists of tests to diagnose labral tears and impingement. A plain x-ray (AP and Lateral views) was taken to rule out degenerative arthritic changes. The patients who were suspected to have soft tissue pathology or signs and symptoms of impingement were then referred for MRI arthrography done by a single musculoskeletal radiologist. The patient demographics are shown in Table 1.

\section{MRI arthrogram technique}

An informed written consent including risk of infection and action to be taken in context of deteriorating symptoms over $72 \mathrm{hr}$ period. Verbal information about post procedural care. Patients are positioned supine on fluoroscopic unit. The affected leg placed in 45 degrees internal rotation and foam pad under knee to flex hip 10 degrees. Skin marked under fluoroscopy guidance. Skin prepared using chloroprep

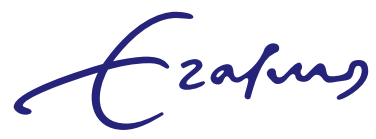


Table 1: Patient demographics

\begin{tabular}{cl}
\hline Age (in years) & \\
Mean & 39.7753 \\
Median & 40.1232 \\
Std. Deviation & 12.08682 \\
Variance & 146.096 \\
Range & 56.87 \\
Minimum & 16.83 \\
Maximum & 73.70 \\
Sex (M/F) & $51 / 62$ \\
Side (R/L) & $59 / 54$ \\
\hline
\end{tabular}

stick and draped. The injection site is infiltrated using 3-5mls $1 \%$ lidocaine to skin. Anterior approach with $22 \mathrm{G}$ spinal needle. Intra-articular position confirmed with $2 \mathrm{mls}$ omnipaque 240 and between $12-16 \mathrm{mls}$ of dilute gadolinium solution (0.2 mls of multihance or prohance diluted in 20mls saline) injected and dressings applied. The patient is then transferred to MRI room in a wheelchair.

The usual sequences done are: Field of View $16 \times 16 \mathrm{~cm}$;Axial oblique and coronal T1 weighted fat saturated; Coronal Proton density fat saturated; Axial T1 Fast spin echo;3d T1 weighted Fast Field Echo.

The hip arthroscopy was performed under image intensifier control with either general or spinal anaesthesia. The patient was put on traction table with appropriate traction applied to distract the joint. A spinal needle was used to locate the joint under fluoroscopy and 70 degrees scopes were used. The central and peripheral compartments were visualised and all the findings were documented. A retrospective analysis of these 113 patients who had MRI arthrogram and who underwent hip arthroscopy were carried out. The findings were then compared to that found on arthroscopy.

\section{Statistical analysis}

The sensitivity, specificity, positive predictive value (PPV), negative predictive value (NPV), accuracy positive likelihood ratio, negative likelihood ratio and disease prevalence and 95\%confidence interval (CI) were calculated for each pathology. The ROC curve is constructed for labral pathology as this was the commonest findings in both MRI arthrogram and hip arthroscopy. The analysis is conducted using IBM SPSS Statistics version 24.0 and MedCalc Statistical Software version 16.8.4 (MedCalc Software bvba, Ostend, Belgium; https://www.medcalc.org; 2016).

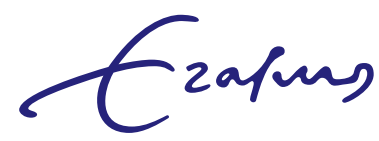




\section{RESULTS}

Labral tears-Sensitivity $83.52 \%$, Specificity $63.64 \%$, PPV $90.48 \%$, NPV $48.28 \%$ and accuracy $79.6 \%$, Table 2, Figure 1.

Femoral-acetabular impingement (CAM deformity)-Sensitivity $34.21 \%$, Specificity 82.67\%, PPV 50.00\%, NPV 71.26\% and accuracy 66.4\%, Table 3, Figure 2.

Chondral changes-Sensitivity $24.49 \%$, Specificity $82.81 \%$, PPV $52.17 \%$, NPV $58.89 \%$ and accuracy $57.5 \%$, Table 4, Figure 3.

Delamination -Sensitivity 6.67\%, Specificity 97.59\%, PPV 50.00\%, NPV 74.31\% and accuracy $38.9 \%$, Table 5, Figure 4 .

Synovitis-Sensitivity 10.71\%, Specificity 98.82\%, PPV 75.0\%, NPV 77.06\% and accuracy $77.0 \%$, Table 6, Figure 5.

Loose bodies-Sensitivity 0.00\%, Specificity 99.11\%, PPV 0.00\%, NPV 99.11\% and accuracy $98.2 \%$, Table 7 .

The ROC for labral tear showed AUC (Area Under the Curve) as 0.736 which is statistically significant ( $\mathrm{P}$ value 0.0003 ) Figure 5 and Table 8 demonstrates the likelihood ratios.

\section{DISCUSSION}

There are several previous studies that compared the findings of MRI arthrogram and hip arthroscopy $[11,12,13$, and 14]. Most of these studies have shown that MRI arthrogram is useful in detecting acetabular labral tears, our study showed that in detecting the labral tears, the sensitivity, specificity and accuracy was slightly lower than the other published studies $[11,12,13]$. The sensitivity varied from 70 to $100 \%$ with majority more than $90 \%$. The specificity varied from 0 to $100 \%$ with most studies showing less than $80 \%$. This may be due to the fact that the other studies had only small patient cohorts compared to 113 patients in our study. The meta-analysis study by Smith et al showed a collective sensitivity of $87 \%$ and specificity of $64 \%$ for MRI arthrograms [15]. This is more or less agreeable with our results of sensitivity $83.5 \%$ and specificity $63.6 \%$.

In the assessment of chondral lesions the sensitivity is usually low and specificity is high as shown in various studies [4, 16, 17]. In our series the sensitivity was $24.5 \%$ and specificity was $82.8 \%$. But the study by Zlatkin et al showed a very high sensitivity of $82 \%[11]$. The meta-analysis study by Smith et al also showed similar conclusions[18]. The diagnosis of cartilage delamination using MRI arthrogram is very demanding. This may be due to the fact that the hip joint distensibility is very much restricted. There are some studies which suggest that a plain MRI scan is more useful to detect cartilage injuries in the hip rather than with MRI arthrogram[19]. Anderson et al showed that for cartilage delamination magnetic

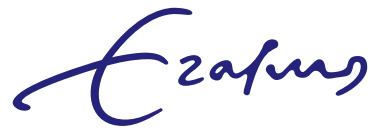


Table 2. Diagnostic test for labral tear-Overall accuracy $-79.6 \%$

\section{Data}

\begin{tabular}{lccc}
\hline & Disease Present & Disease Absent & \\
\hline Test Positive & 76 & 8 & 29 \\
Test Negative & 15 & 14 & 22 \\
& 91 & & \\
\hline Results & & $74.27 \%$ to $90.47 \%$ \\
\hline Sensitivity & $83.52 \%$ & $40.66 \%$ to $82.80 \%$ \\
Specificity & $63.64 \%$ & 0.64 to 0.81 \\
AUC & 0.74 & 1.31 to 4.02 \\
Positive Likelihood Ratio & 2.30 & 0.15 to 0.45 \\
Negative Likelihood Ratio & 0.26 & $72.02 \%$ to $87.38 \%$ \\
Disease prevalence & $80.53 \%$ & $82.09 \%$ to $95.80 \%$ \\
Positive Predictive Value & $90.48 \%$ & $29.45 \%$ to $67.47 \%$ \\
\hline
\end{tabular}

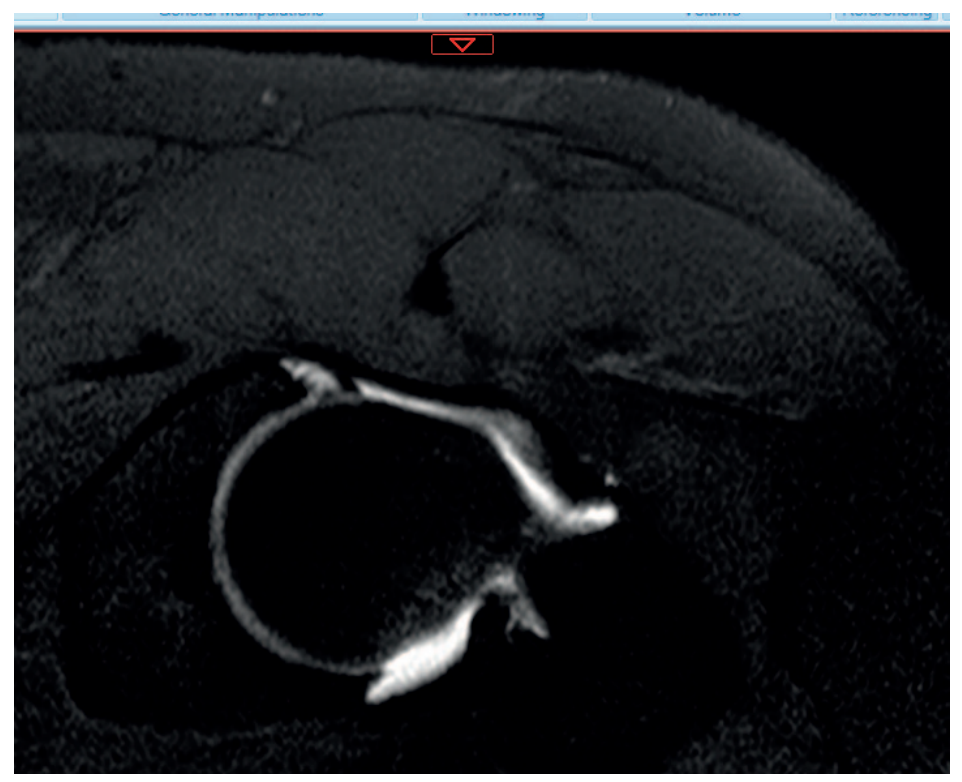

Figure 1. Axial oblique T1 fat saturated weighted MR arthrogram image showing acetabular labral tear. 
Table 3. Diagnostic test CAM and FAI-Overall accuracy- $66.4 \%$

\section{Data}

\begin{tabular}{|c|c|c|c|}
\hline & Disease Present & Disease Absent & \\
\hline Test Positive & 13 & 13 & 26 \\
\hline \multirow[t]{2}{*}{ Test Negative } & 25 & 62 & 87 \\
\hline & 38 & 75 & \\
\hline \multicolumn{4}{|l|}{ Results } \\
\hline Sensitivity & & $34.21 \%$ & $19.63 \%$ to $51.35 \%$ \\
\hline Specificity & & $82.67 \%$ & $72.19 \%$ to $90.43 \%$ \\
\hline AUC & & 0.58 & 0.49 to 0.68 \\
\hline Positive Likelihood Ratio & & 1.97 & 1.02 to 3.83 \\
\hline Negative Likelihood Ratio & & 0.80 & 0.62 to 1.02 \\
\hline Disease prevalence & & $33.63 \%$ & $25.01 \%$ to $43.12 \%$ \\
\hline Positive Predictive Value & & $50.00 \%$ & $29.93 \%$ to $70.07 \%$ \\
\hline Negative Predictive Value & & $71.26 \%$ & $60.57 \%$ to $80.46 \%$ \\
\hline
\end{tabular}

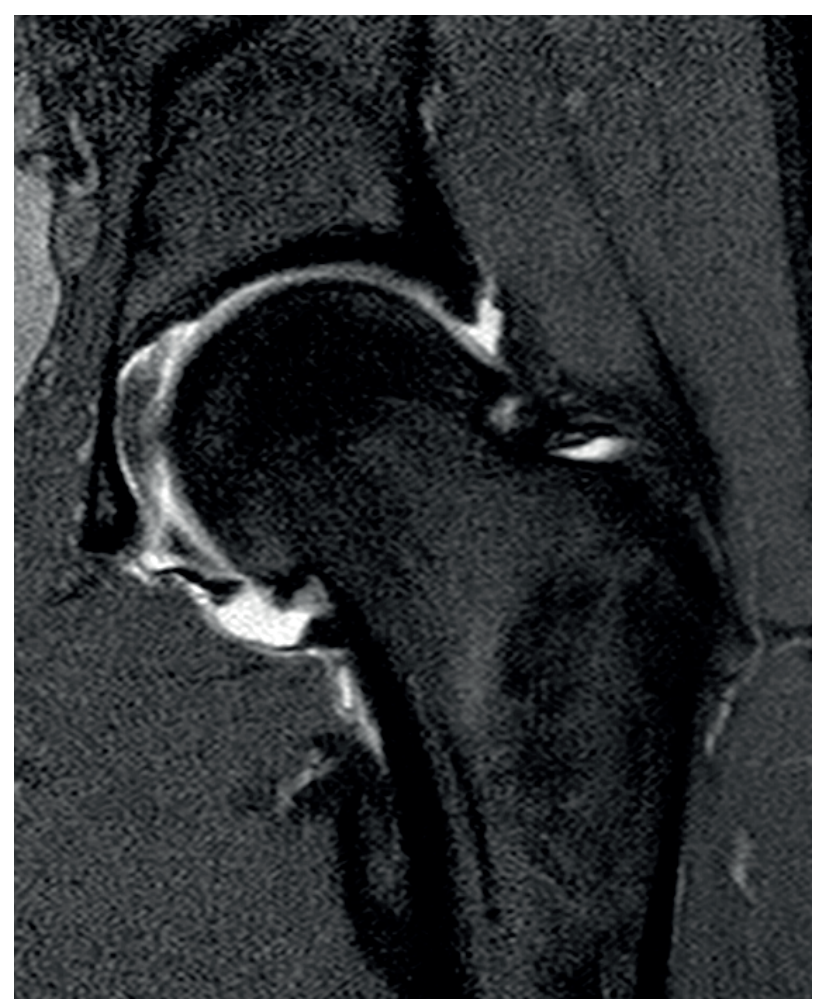

Figure 2. Coronal T2 fat saturated weighted MR arthrogram image showing femoral head osteophytes

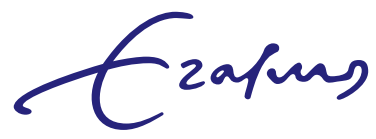


Table 4. Diagnostic test Chondral changes-Overall accuracy $-57.5 \%$

Data

\begin{tabular}{lcrr}
\hline & Disease Present & \multicolumn{2}{c}{ Disease Absent } \\
\hline Test Positive & 12 & 11 & 23 \\
Test Negative & 37 & 53 & 90 \\
& 49 & 64 & $13.34 \%$ to $38.87 \%$ \\
\hline Results & & $71.32 \%$ to $91.10 \%$ \\
\hline Sensitivity & $24.49 \%$ & 0.44 to 0.63 \\
Specificity & $82.81 \%$ & 0.69 to 2.95 \\
AUC & 0.54 & 0.75 to 1.11 \\
Positive Likelihood Ratio & 1.42 & $34.07 \%$ to $53.01 \%$ \\
Negative Likelihood Ratio & 0.91 & $30.59 \%$ to $73.18 \%$ \\
Disease prevalence & $43.36 \%$ & $48.02 \%$ to $69.16 \%$ \\
Positive Predictive Value & $52.17 \%$ & $58.89 \%$ & \\
Negative Predictive Value & & & \\
\hline
\end{tabular}

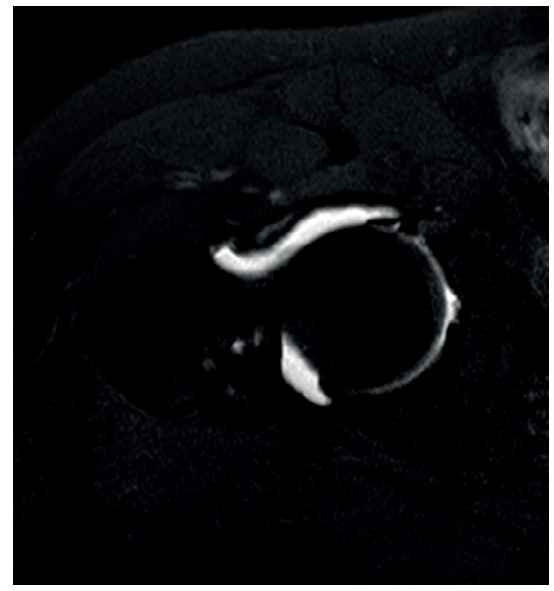

Figure 3a. Axial oblique T1 weighted Fat saturated arthrogram image which demonstrates a small focus of full thickness anterior acetabular chondral deficit

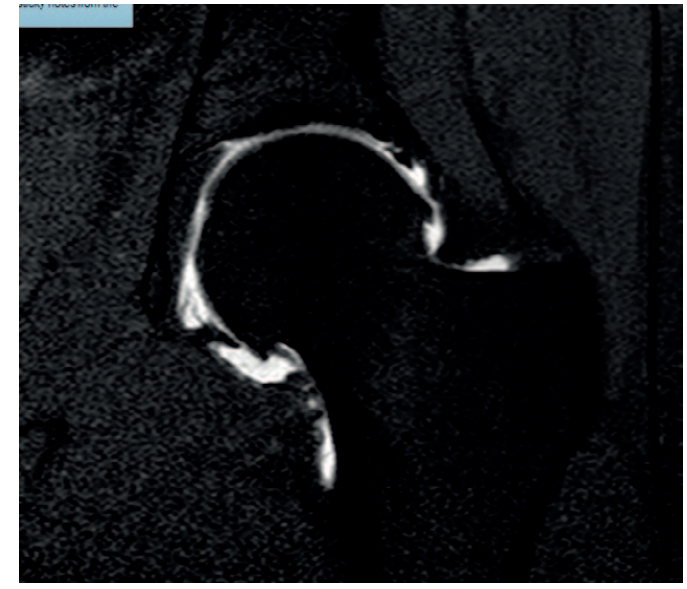

Figure 3b. Coronal T1 weighted Fat saturated arthrogram picture showing acetabular chondral delamination/grade 4 chondral changes in the lateral acetabulum 
Table 5. Diagnostic test Delamination -Overall accuracy-73.5\%

\begin{tabular}{lcrr} 
Data & Disease Present & \multicolumn{3}{c}{ Disease Absent } \\
\hline Test Positive & 2 & 2 & 4 \\
Test Negative & 28 & 81 & 109 \\
& 30 & 83 & \\
\hline Results & & & $0.82 \%$ to $22.07 \%$ \\
\hline Sensitivity & $6.67 \%$ & $91.57 \%$ to $99.71 \%$ \\
Specificity & $97.59 \%$ & 0.43 to 0.62 \\
AUC & 0.52 & 0.41 to 18.78 \\
Positive Likelihood Ratio & 2.77 & 0.86 to 1.06 \\
Negative Likelihood Ratio & 0.96 & $18.68 \%$ to $35.68 \%$ \\
Disease prevalence & $26.55 \%$ & $6.76 \%$ to $93.24 \%$ \\
Positive Predictive Value & $50.00 \%$ & $65.06 \%$ to $82.20 \%$ \\
Negative Predictive Value & $74.31 \%$ & & \\
\hline
\end{tabular}

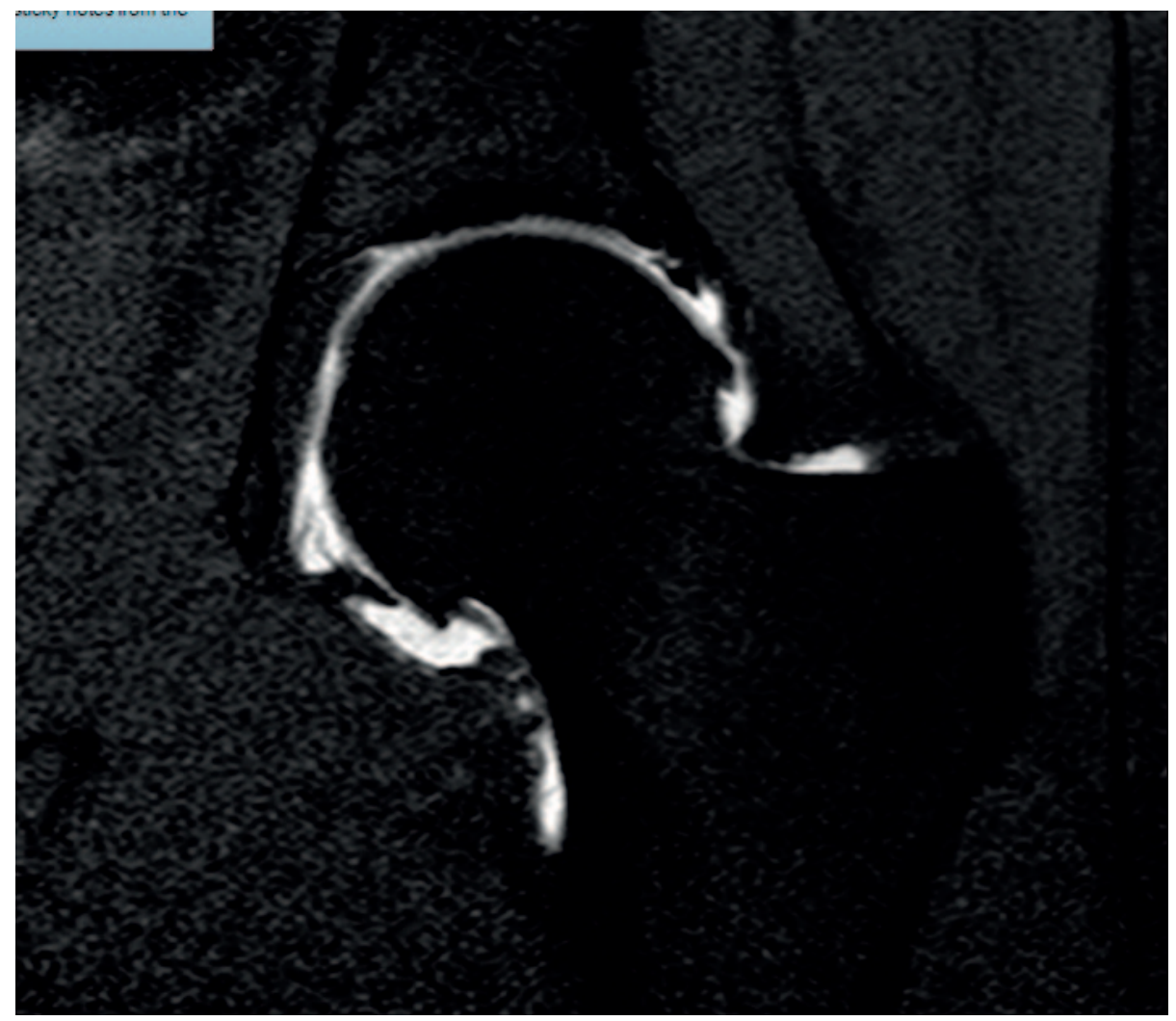

Figure 4. Coronal T1 weighted Fat saturated arthrogram image showing acetabular delamination in the lateral acetabulum

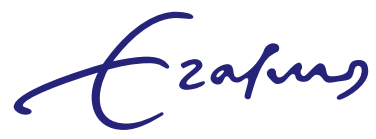


Table 6. Diagnostic test Synovitis-overall accuracy-77.0\%

\begin{tabular}{|c|c|c|c|}
\hline & Disease Present & & \\
\hline Test Positive & 3 & & 4 \\
\hline \multirow[t]{2}{*}{ Test Negative } & 25 & & 109 \\
\hline & 28 & & \\
\hline \multicolumn{4}{|l|}{ Results } \\
\hline Sensitivity & & $10.71 \%$ & $2.27 \%$ to $28.23 \%$ \\
\hline Specificity & & $98.82 \%$ & $93.62 \%$ to $99.97 \%$ \\
\hline AUC & & 0.55 & 0.45 to 0.64 \\
\hline Positive Likelihood Ratio & & 9.11 & 0.99 to 84.07 \\
\hline Negative Likelihood Ratio & & 0.90 & 0.79 to 1.03 \\
\hline Disease prevalence & & $24.78 \%$ & $17.14 \%$ to $33.78 \%$ \\
\hline Positive Predictive Value & & $75.00 \%$ & $19.41 \%$ to $99.37 \%$ \\
\hline Negative Predictive Value & & $77.06 \%$ & $68.03 \%$ to $84.57 \%$ \\
\hline
\end{tabular}

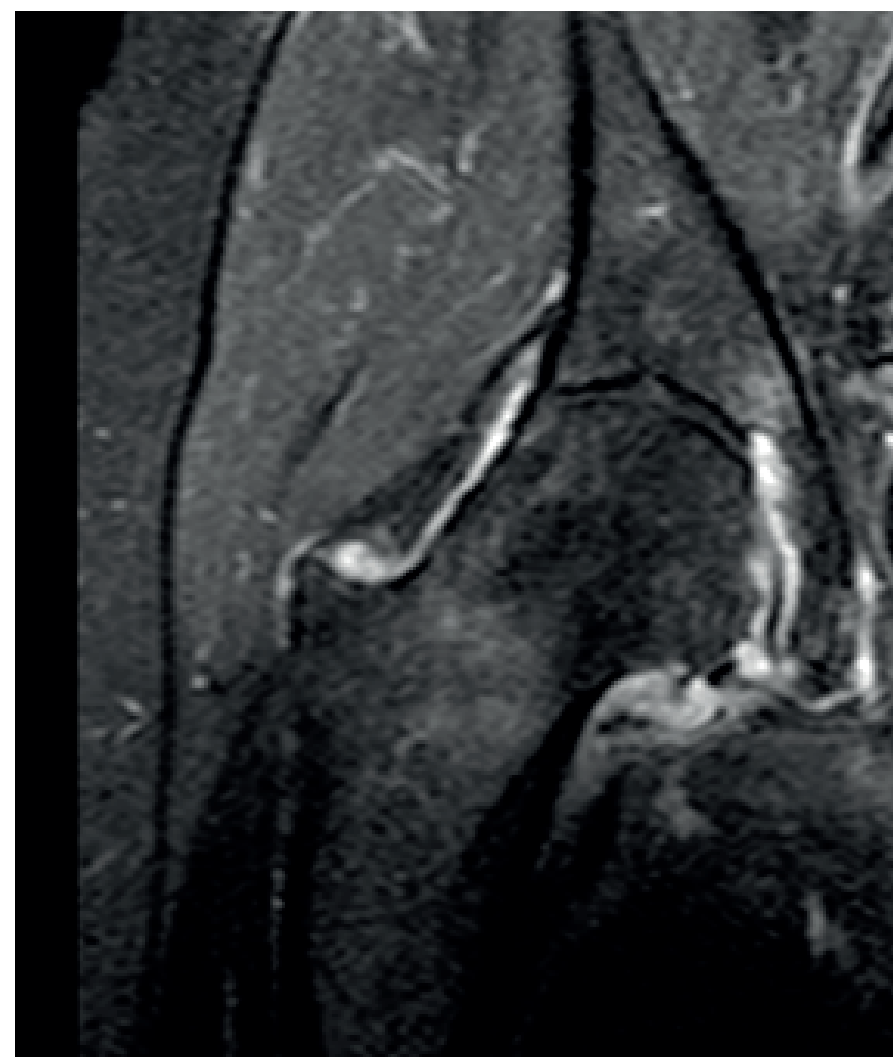

Figure 5. Coronal T1 weighted fat saturated images demonstrates synovitis throughout the hip joint

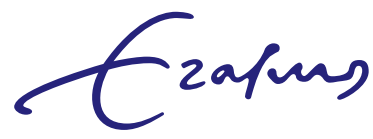


Table 7. Diagnostic test Loose bodies-overall accuracy-98.2\%

Data

\begin{tabular}{lcrr}
\hline & Disease Present & \multicolumn{2}{c}{ Disease Absent } \\
\hline Test Positive & 0 & 1 & 1 \\
Test Negative & 1 & 111 & 112 \\
& 1 & & 112 \\
Results & & $0.00 \%$ & $0.00 \%$ to $97.50 \%$ \\
\hline Sensitivity & $99.11 \%$ & $95.13 \%$ to $99.98 \%$ \\
Specificity & 0.50 & 0.40 to 0.59 \\
AUC & 0.00 & 0.99 to 1.03 \\
Positive Likelihood Ratio & 1.01 & $0.02 \%$ to $4.83 \%$ \\
Negative Likelihood Ratio & $0.88 \%$ & $0.00 \%$ to $97.50 \%$ \\
Disease prevalence & $0.00 \%$ & $95.13 \%$ to $99.98 \%$ \\
Positive Predictive Value & $99.11 \%$ & & \\
Negative Predictive Value & & & \\
\hline
\end{tabular}

Table 8. Criterion values and coordinates of the ROC curve

\begin{tabular}{lrrrrrrrr}
\hline Criterion & Sensitivity & $95 \% \mathrm{Cl}$ & Specificity & $95 \% \mathrm{Cl}$ & $+\mathrm{LR}$ & $95 \% \mathrm{Cl}$ & $-\mathrm{LR}$ & $95 \% \mathrm{Cl}$ \\
\hline$\geq 0$ & 100.00 & $96.0-100.0$ & 0.00 & $0.0-15.4$ & 1.00 & $1.0-1.0$ & & \\
$>0$ & 83.52 & $74.3-90.5$ & 63.64 & $40.7-82.8$ & 2.30 & $1.3-4.0$ & 0.26 & $0.1-0.5$ \\
$>1$ & 0.00 & $0.0-4.0$ & 100.00 & $84.6-100.0$ & & & 1.00 & $1.0-1.0$ \\
\hline
\end{tabular}

resonance arthrography had a low sensitivity of $22 \%$ but had a high specificity of $100 \%$ [20]. In our study also the sensitivity for detecting cartilage delamination using MRI arthrogram is very low of $6.67 \%$ but very high specificity of $97.59 \%$ which is in agreement with other published studies.

One of the commonest causes of pain in young adult hip is femoro-acetabular impingement (FAI) [21]. MRI arthrogram is useful tool in the diagnosis of femoroacetabular impingement. Notzli et al compared the MRI images of patient with FAI with control subjects and measured the alpha angle. They proposed that an alpha angle of more than 55 degrees is diagnostic of FAI[22]. The published studies by Aprato et al demonstrated that the sensitivity of MRI arthrogram for FAI was $46 \%$ and specificity was $81 \%[23]$. This comparable to our findings for FAI with sensitivity of 34.25 and specificity of $82.7 \%$.

The usual pathology causing mechanical symptoms and thereby giving rise to painful hip are the presence of intra articular loose bodies[24]. Intra articular loose bodies form as result of acute or chronic injury, osteochondritis dissecans and synovial osteochondromatosis[25]. They can be fibrous, cartilaginous, osseous or a mixture of composition of these tissues[26,27]. The loose bodies can be of various shapes and sizes[28]. Neckers et al in their study has shown that in the detection

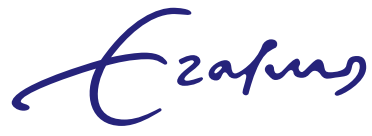


of loose bodies using MRI arthrogram, the specificity was $96 \%$ and sensitivity $44 \%[29]$. They recommended that ultrasound and CT scans with or without air or saline would give better results than MRI arthrogram.

There are no studies in the literature looking at the accuracy and usefulness in the diagnosis of synovitis of the hip using MRI arthrogram. In our study we found that the sensitivity was very low of $10 \%$ and very high specificity of $98 \%$.

Aprato et al in their study reviewed 60 patients who had undergone a revision hip arthroscopy. Patients were divided into two groups, Group 1 which included 40 patients who had undergone arthroscopic labral surgery and Group 2 of 20 patients who had not undergone labral surgery. Sensitivity for MRA after hip arthroscopy was $53 \%$ and $71 \%$ in the study and control groups, respectively. The specificity was $50 \%$ and $92 \%$, positive predictive value was $81 \%$ and $83 \%$, negative predictive value was $21 \%$ and $86 \%$ and accuracy was $53 \%$ and $85 \%$. They concluded that the MRA is not reliable after hip arthroscopy where a labral tear has been repaired[30].

Another recent study by Reurink et al concluded that when there is a high clinical suspicion of a labral lesion, magnetic resonance arthrography has a poor negative predictive [31]. In the recent study by Crespo Rodriguez et al, they found that the sensitivity and specificity of MR arthrography were $94.5 \%$ and $100 \%$, respectively for labral tears and $92.5 \%$ and $54.5 \%$, respectively for diagnosing lesions of the articular cartilage. These findings are not in agreement with our study which showed only $25 \%$ sensitivity for articular cartilage lesions. But they concluded that the diagnostic accuracy of MR arthrogram was not so good in small chondral lesions [32].

Limitations of the study: Our study is a retrospective analysis of 113 MR arthrograms findings compared with that found at hip arthroscopy. The cohort of patient numbers is small. The results of MR arthrogram was interpreted by one radiologist thereby inter- observer variability could not be assessed.

Future Directions: A prospective study with large group of patients with two observers should be carried out to reduce intra and inter observer variability so that the results will be statistically more significant.

Conclusion: In our study MRI arthrogram of the hip is a useful diagnostic tool in detecting labral, femoral acetabular impingement with accuracy of $80 \%$ and $66 \%$ respectively. But in the diagnosis of cartilage pathology including delamination and chondral defects the accuracy was $39 \%$ and $58 \%$ respectively. 


\section{REFERENCES}

1. Feeley B, Powell J, Muller M, Barnes R, Warren R, Kelly B. Hip injuries and labral tears in the national football league. The American Journal of Sports Medicine 2008;(36):21872195.

2. Edwards DJ, Lomas D, Villar RN. Diagnosis of the painful hip by magnetic resonance imaging and arthroscopy. J Bone J Surg. 1995;77B: 374-376.

3. Czerny C, Hofmann S, Neuhold A, Tschauner C, Engel A, Recht MP, Kramer J. Lesions of the acetabular labrum: accuracy of MR imaging and MR arthrography in detection and staging. Radiology 1996; 200:225-230.

4. Schmid MR, Notzli HP, Zanetti M, Wyss TF, Hodler J. Cartilage lesions in the hip: diagnostic effectiveness of MR Arthrography. Radiology 2003;226:382-386.

5. Petersilge CA. MR arthrography for evaluation of the acetabular labrum. Skeletal Radiol. 2001; 30(8):423 30.

6. Lubowitz JH, Poehling GG. Hip arthroscopy: an emerging gold standard. Arthroscopy. 2006; 22(12):1257-9.

7. Baber YF, Robinson AHN, Villar RN. Is diagnostic arthroscopy of the hip worthwhile? A prospective review of 328 adults investigated for hip pain. J Bone J Surg. 1999; 81B: 600-603.

8. O'Leary JA, Berend K, Vail TP. The relationship between diagnosis and outcome in arthroscopy of the hip. Arthroscopy 2001; 17:181-188.

9. Clement N D, MacDonald D, Gaston P. Hip arthroscopy for femoroacetabular impingement: a health economic analysis. Hip International. 2014; 24 (5):457-464.

10. Locher S, Werlen S, Leunig M, Ganz R. MR-Arthrography with radial sequences for visualization of early hip pathology not visible on plain radiographs. [Article in German]. Z Orthop Ihre Grenzgeb. 2002 Jan-Feb; 140(1):52-57

11. Zlatkin MB, Pevsner D. Sanders TG, Hancock CR, Ceballos CE, Herrera MF. Acetabular labral tears and cartilage lesions of the hip: indirect MR arthrographic correlation with arthroscopy—a preliminary study. AJR Am J Roentgenol. 2010 Mar: 194(3):709-14.

12. Byrd JW, Jones KS. Diagnostic accuracy of clinical assessment, magnetic resonance imaging, magnetic resonance arthrography, and intra-articular injection in hip arthroscopy patients. Am J Sports Med. 2004 Oct-Nov: 32(7):1668-74.

13. Chan YS, Lien LC, Hsu HL, Wan YL, Lee MS, Hsu KY, Shih CH. Evaluating hip labral tears using magnetic resonance arthrography: a prospective study comparing hip arthroscopy and magnetic resonance arthrography diagnosis. Arthroscopy 2005: 21:1250.

14. Keeney JA, Peelle MW. Jackson J. Rubin D, Maloney WJ, Clohisy JC. Magnetic resonance arthrography versus arthroscopy in the evaluation of articular hip pathology. Clin Orthop Relat Res. 2004 Dec:(429):163-9.

15. Smith TO, Hilton G, Toms AP, Donell ST, Hing CB. The diagnostic accuracy of acetabular labral tears using magnetic resonance imaging and magnetic resonance arthrography: a meta-analysis. Eur Radiol 2011; 21:863-874.

16. Pfirrmann CW, Duc SR, Zanetti M, Dora C, Hodler J. MR arthrography of acetabular cartilage delamination in femoroacetabular cam impingement. Radiology 2008; 249: 236-241

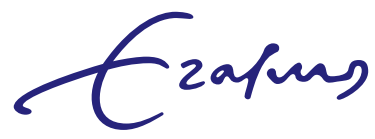


17. Anderson LA, Peters CL, Park BB, Stoddard GJ, Erickson JA, Crim JR. Acetabular cartilage delamination in femoroacetabular impingement: risk factors and magnetic resonance imaging diagnosis. J Bone Joint Surg Am 2009; 91:305-31

18. Smith TO, Simpson M, Ejindu V, Hing CB. The diagnostic test accuracy of magnetic resonance imaging, magnetic resonance arthrography and computer tomography in the detection of chondral lesions of the hip. Eur J Orthop Surg Traumatol 2013; 23:335-344

19. Mintz DN, Hooper T, Connell D, Buly R, Padgett DE, Potter HG. Magnetic resonance imaging of the hip: detection of labral and chondral abnormalities using noncontrast imaging. Arthroscopy 2005; 21:385-393.

20. Anderson LA, Peters CL, Park BB, Stoddard GJ, Erickson JA, Crim JR. Acetabular cartilage delamination in femoroacetabular impingement. Risk factors and magnetic resonance imaging diagnosis. J Bone J Surg Am. 2009; 91:305-313.

21. Ganz R, Parvizi J, Beck M, Leunig M, Notzli H, Siebenrock KA. Femoroacetabular impingement: a cause for osteoarthritis of the hip. Clin Orthop Relat Res. 2003; 417:112-120.

22. Notzli HP, Wyss TF, Stoecklin $\mathrm{CH}$, Schmid MR, Treiber K, Hodler J. The contour of the femoral head-neck junction as a predictor for the risk of anterior impingement. J Bone Joint Surg Br. 2002; 84:556-60.

23. Aprato A, Masse A, Faletti C, Valente A, Atzori F, Stratta M, Jayasekera N. Magnetic resonance arthrography for femoroacetabular impingement surgery: is it reliable? J Orthopaed Traumatol (2013) 14:201-206.

24. Newberg AH, Newman JS. Imaging the painful hip. Clin Orthop Relat Res 2003; 406: 19-28.

25. Krebs VE. The role of hip arthroscopy in the treatment of synovial disorders and loose bodies. Clin Orthop Relat Res 2003; 406: 48-59.

26. Milgram JW. The classification of loose bodies in human joints. Clin Orthop Relat Res 1977; 124: 282-291.

27. Milgram JW. The development of loose bodies in human joints. Clin Orthop Relat Res 1977; 124: 292-303.

28. Rai NN, Siney PD, Fleming PA, Wroblewski BM. Incidence of loose bodies in an osteoarthritic hip. J R Coll Surg Edinb 2001; 46: 274-276.

29. Neckers AC, Polster JM, Winalski CS, Krebs VE, Sundaram M. Comparison of MR arthrography with arthroscopy of the hip for the assessment of intra-articular loose bodies. Skeletal Radiol. 2007; 36(10):963-7.

30. Aprato A, Jayasekera N, Villar RN. The accuracy of magnetic resonance arthrography in hip arthroscopic labral revision surgery. Hip Int. 2013 Jan-Feb;23(1):99-103.

31. Reurink G, Jansen SP, Bisselink JM, Vincken PW, Weir A, Moen MH. Reliability and validity of diagnosing acetabular labral lesions with magnetic resonance arthrography. J Bone Joint Surg Am. 2012 Sep 19; 94(18):1643-1648.

32. Crespo Rodríguez AM, de Lucas Villarrubia JC, Pastrana Ledesma MA, Millán Santos I, Padrón M. Diagnosis of lesions of the acetabular labrum, of the labral-chondral transition zone, and of the cartilage in femoroacetabular impingement: Correlation between direct magnetic resonance arthrography and hip arthroscopy. Radiologia. 2015 MarApr; 57(2):131-141. 


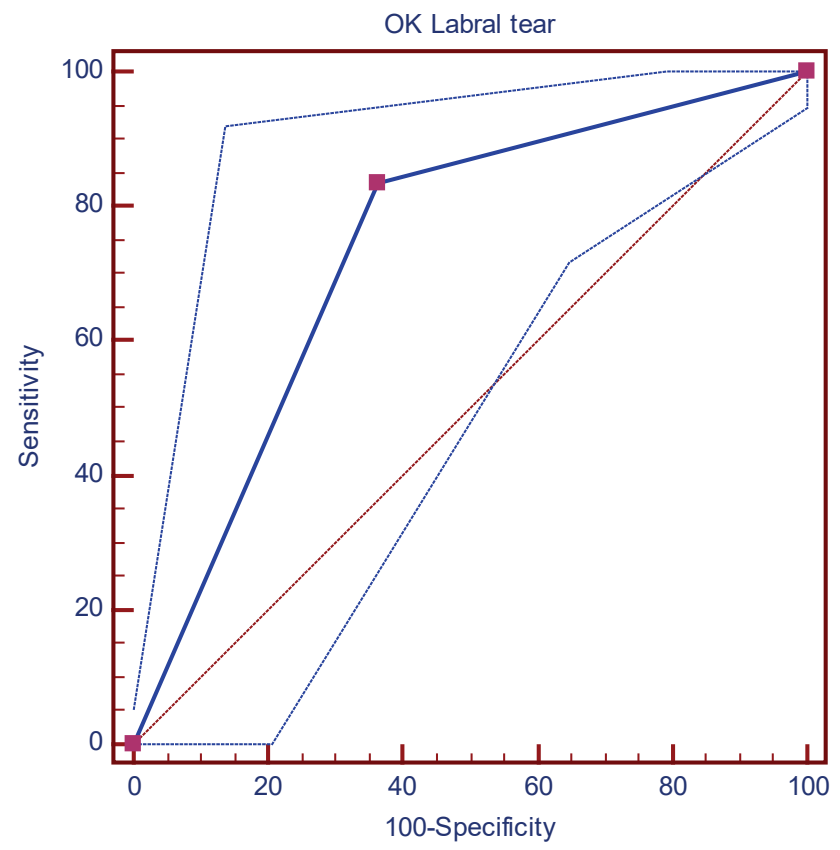

Figure 6. ROC curve for labral tear solid line showing the test and dashed lines showing likelihood ratios. The AUC is 0.74 with $95 \% \mathrm{Cl}-0.645$ to 0.814 . 